\title{
Magnitude of Diabetic Neuropathy in Saudi Arabia: A Systematic Review and Meta-Analysis
}

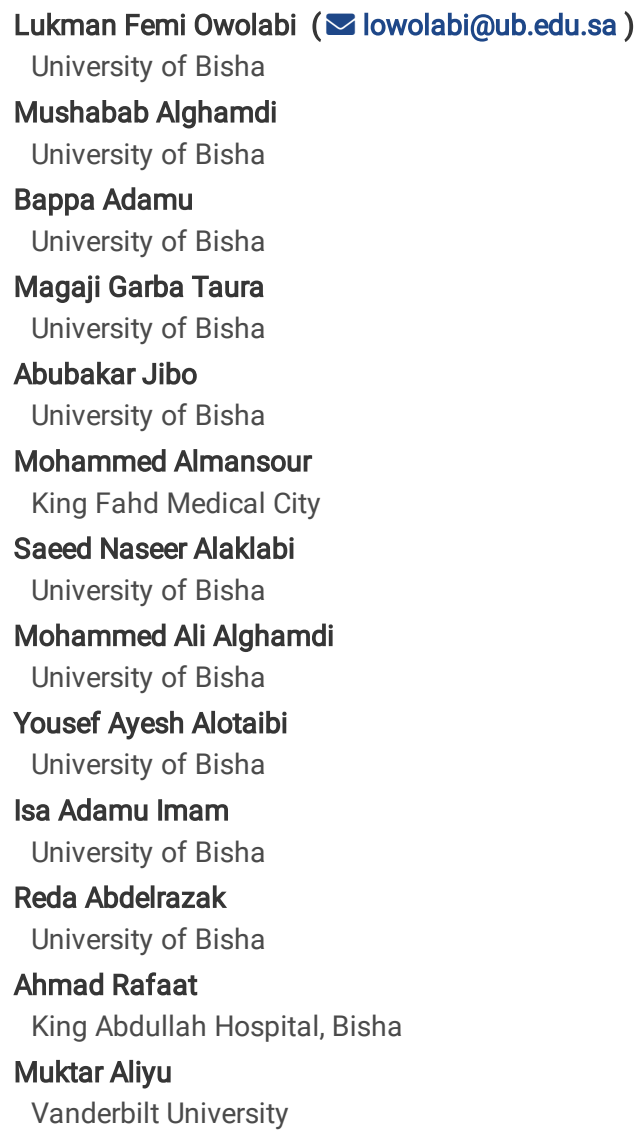




\section{Abstract}

Background: Diabetic peripheral neuropathy (DPN), due to its potential for causing morbidity and disability from foot ulcers and amputations, is increasingly becoming a source of concern in Saudi Arabia and worldwide. However, wide variability exists in the prevalence of DPN reported in previous studies in Saudi Arabia, limiting the utility of existing data in national public health policy. Therefore, this study aimed to estimate the magnitude of DPN in people living with diabetes mellitus in Saudi Arabia.

Methods: PubMed, Google Scholar, African Journals OnLine, Scopus, Web of Science, Embase, and Wiley Online Library were searched systematically to acquire relevant articles based on preset criteria. We evaluated heterogeneity and publication bias and employed a random-effects model to estimate the pooled prevalence of DPN from the included studies. We followed the Preferred Reporting Items for Systematic Reviews and Meta-Analyses guidelines in conducting the meta-analysis. Analysis was performed using the STATA Version 12 software.

Results: Twelve studies with a total of 4,556 participants were included in the meta-analysis. The overall prevalence of DPN was 39\% (95\% Cl [30\%, 49\%]). Subgroup analysis based on diagnostic method showed that prevalence estimates for DPN using screening questionnaires and clinical examination were $48 \%(95 \% \mathrm{Cl}[46 \%, 50 \%])$ and $40 \%$ (95\% Cl: [38\%, 42\%]), respectively, while the estimated prevalence using nerve conduction studies was 26\% (95\% Cl [15\%, $36 \%])$.

Conclusion: This study showed a high magnitude of DPN in Saudi Arabia (39\%), thus highlighting the need for sustained efforts to reduce the prevalence of diabetes mellitus and DPN in the kingdom.

\section{Introduction}

Diabetes mellitus (DM) remains a major worldwide health concern, and diabetic peripheral neuropathy (DPN) is the most common cause of peripheral neuropathy globally. ${ }^{1}$ According to consensus, DPN is defined as a symmetrical and length-dependent sensorimotor polyneuropathy resulting from alteration in metabolism and small vessels caused by the prolonged effect of hyperglycemia and metabolic abnormalities. ${ }^{2}$ Nearly half of those with DM have DPN, and 1-2 out of 10 patients with DPN have severe cases that warrant treatment. 3,4

DM is undoubtedly one of the most challenging health problems facing Saudi Arabia. ${ }^{5}$ The Ministry of Health of Saudi Arabia estimated that the number of people diagnosed with DM rose from approximately 0.9 million people in 1992 to 2.5 million people in 2010, representing an almost 3-fold increase in incidence over less than 2 decades. ${ }^{6} \mathrm{~A}$ recent meta-analysis of observational studies in Saudi Arabia reported type 2 DM, type 1 DM, and overall point prevalence rates of $20.9 \%, 0.9 \%$, and $12.6 \%$, respectively. ${ }^{7}$

DM is associated with morbidity and mortality of public health significance. Complications associated with DM are increasingly a source of concern in several Arab populations. ${ }^{8}$ Notable among the numerous complications of DM is DPN, a common microvascular complication with an attendant risk of ulceration and amputation ${ }^{9}$ that accounts for a large economic burden of diabetes care.

Globally, DPN places a large economic burden on both people living with DM and national healthcare systems. The annual cost of treatment for DPN and its related complications in people living with DM in the United States was estimated at US\$10.91 billion. ${ }^{10}$ The care of diabetic foot, a common complication of DPN, accounted for approximately $0.6 \%$ of National Health Service expenditures between 2010 and $2011 .{ }^{11}$ Though there is a paucity of data on the total cost of treating people with DM in Saudi Arabia, the national healthcare burden of diabetes was, without considering indirect costs, estimated to exceed US\$0.87 billion. ${ }^{12}$ DPN thus contributes significantly to the health expenditures of both Saudi Arabia and the world at large. Therefore, knowledge of the magnitude of DPN to inform policies relating to controlling the substantial health expenditures from DPN is a country-specific as well as a global concern.

Wide variability exists in the prevalence of DPN reported in previous studies. Estimates of the magnitude of DPN include $56.2 \%$ in Yemen, ${ }^{13} 48.1 \%$ in Sri Lanka, ${ }^{14} 46 \%$ in Africa, ${ }^{15} 39.5 \%$ in Jordan, ${ }^{16} 29.2 \%$ in India, ${ }^{17} 8.4 \%$ in China, ${ }^{18} 20 \%$ in France, ${ }^{19}$ and $11 \%-25 \%$ in the United States. ${ }^{20,21}$ A systematic review conducted on painful DPN reported a point prevalence of $43.2 \%$, though the review included only 1 study from Saudi Arabia. ${ }^{22}$

In Saudi Arabia, data on the prevalence of DPN vary remarkably by study, with reported DPN prevalence rates ranging from $20 \%{ }^{23}$ to $66.7 \%{ }^{24}$ However, most of these reports had small sample sizes, limiting the extent to which they can be used as national figures of the magnitude of DPN. This marked variation in DPN prevalence estimates could be ascribed to heterogeneity across studies in study design, risk factors, population demographics, and case ascertainment, constraining the use of existing data to estimate the number of people in Saudi Arabia with DPN and guide national public health policy.

The aim of this study was thus to systematically evaluate the magnitude of DPN in patients living with DM in Saudi Arabia in order to inform policymakers during the implementation of appropriate preventive and treatment strategies for DPN.

\section{Materials And Method}

\section{Literature search}

We searched the electronic databases PubMed, Google Scholar, African Journals OnLine, Scopus, Web of Science, Embase, and Wiley Online Library. Cambridge Middle East Library and Cochrane Reviews were also searched. Furthermore, we performed a hand search of grey literature and other related 
articles as well as a review of the reference lists of already gathered articles in order to retrieve additional relevant studies. A combination of Medical Subject Heading search terms related to DPN ("diabetic peripheral neuropathy," "peripheral neuropathy in diabetics," "diabetic neuropathy," "prevalence," "magnitude," "Saudi Arabia," "Kingdom of Saudi Arabia"), employed in combination with Boolean operators such as AND and OR to connect search terms, comprised the search strategy. To reduce potential publication bias, we also searched conference proceedings, technical reports on DPN, and medical organization websites. The search was carried out between July 1, 2020, and January 30, 2021. Independent searches were conducted by both the investigators and a librarian.

\section{Selection criteria and process}

\section{Inclusion criteria}

Studies were included if they met the following criteria: (1) the studies had cross-sectional or case-control designs investigating the prevalence or magnitude of DPN, (2) DM and DPN diagnoses were medically confirmed, (3) outcome prevalence or magnitude was reported as the outcome variable or prevalence was not reported but sufficient data was present to compute prevalence of DPN, and (4) the studies were conducted on the Saudi population.

\section{Exclusion criteria}

Studies were excluded based on the following criteria: (1) they provided inadequate or ambiguous information regarding the prevalence or mode of diagnosis of overweight and obesity or (2) they provided prevalence estimates for biased populations, such as populations of pregnant women or prison inmates.

\section{Data extraction}

We extracted relevant data for this systematic review using a Microsoft Excel form designed to capture the information of interest from each article.

For each included study, we obtained information regarding the author, year of study, year of publication, study setting, study type, study population, data collection and analysis methods, and mean age of study participants. We used the name of the study's first author and the year of publication to code the data. After extracting the data independently, the investigators verified all data against the predetermined inclusion and exclusion criteria.

We initially screened the titles and abstracts of all gathered articles and then conducted a full-text review to identify articles that were eligible for further review. Potentially eligible studies were reviewed independently by 2 investigators. Any disagreements were reconciled by discussion or by the third investigator.

\section{Quality assessment and reporting format}

We performed the meta-analysis based on the Meta-analyses of Observational Studies in Epidemiology (MOOSE) ${ }^{25}$ guidelines and the Preferred Reporting Items for Systematic Reviews and Meta-Analyses (PRISMA) statement ${ }^{26}$ (Figure 1). The Agency for Healthcare Research and Quality (AHRQ) checklist for cross-sectional reports was utilized to assess the methodological quality of the included studies. Two investigators carried out the assessment of study quality and any disagreements at the time of quality scoring were reconciled by discussion and by the third investigator.

\section{Data analysis}

The prevalence (P) estimate of DPN in Saudi Arabia was the outcome of primary interest in this review. For each selected study, the prevalence of DPN was calculated and expressed as percentages with $95 \%$ confidence intervals (Cls). A binomial probability distribution was employed to determine the standard error of the prevalence. The log of the prevalence $(\log P)$ and the standard error of logP were calculated for all selected studies. Using a randomeffects model (REM) proposed by DerSimonian and Laird, summary estimates of DPN prevalence and $95 \%$ Cls were generated. ${ }^{27}$ We used between-study heterogeneity tests, Cochran's Q chi-squared statistics, and $\mathrm{I}^{2}$ statistics to assess the random variations between studies. Results with $\mathrm{I}^{2}>50 \%$ were considered to reflect substantial heterogeneity. Potential random variations between the point estimates of the studies were minimized and the sources of heterogeneity observed in the analysis were investigated through meta-regression, subgroup analysis, and sensitivity analysis.

We assessed publication bias and small-study effects by visual inspection of the funnel plot. Egger's regression asymmetry test and Begg's adjusted rank correlation test were also conducted to identify the presence of publication bias. ${ }^{28,29} \mathrm{~A} p$ value $\leq 0.05$ was considered statistically significant for the presence of publication bias. In order to reduce the inconsistency and insensitivity that may arise from these tests, ${ }^{30}$ we considered the existence of publication bias if it was determined by both tests.

The meta-analysis was performed using the STATA version 12 statistical software for Windows (Stata Corp., College Station, TX, USA).

\section{Results}

\section{Study identification and selection}

Our search strategy yielded 247 initial unique citations. After the removal of duplicate articles, there were 134 articles that were potentially relevant (Figure 1). The screening of titles and abstracts based on the exclusion criteria resulted in the removal of 95 articles, with 39 articles remaining for full-text evaluation. After a detailed evaluation, 23 articles were excluded due to a lack of usable data and other reasons (Figure 1). Finally, 11 cross-sectional 
studies $^{8,24,31-39}$ and 1 prospective study ${ }^{40}$ were assessed for their quantitative analysis (Figure 1). Three additional studies ${ }^{41-43}$ were removed due to their retrospective design.

The studies that met the predetermined criteria consisted of a total of 4,556 people living with DM, of whom 2,081 were identified as having DPN. These studies were included in the final analysis. The results of the quality assessment based on AHRQ standards are shown in Table 1, while the characteristics of the included studies are presented in Table 2.

\section{Risk of bias assessment}

As retrospective studies found in our literature searches were not considered for the final analysis, the included studies were cross-sectional and prospective studies, with no case-control studies. Three ${ }^{32,36,40}$ of the cross-sectional studies were used in the final analysis because they used 2 diagnostic methods (questionnaire-based and nerve conduction studies) and arrived at 2 different prevalence estimates for the same population.

\section{Overall prevalence of diabetic peripheral neuropathy in Saudi Arabia}

The overall estimated prevalence of DPN in Saudi Arabia based on the included studies was 39\% (95\% Cl [30\%, 49\%]; Figure 2). The I test revealed marked heterogeneity $\left(I^{2}=98.2 \%\right.$ and $\left.p<0.001\right)$. Egger's test for small-study effects showed evidence of publication bias $(p<0.0001)$. Begg's test also showed publication bias $(p<0.0001)$. In agreement with these results, the funnel plot was asymmetric even after adjusting for potential publication bias by applying the trim-and-fill method (Figure 3).

\section{Publication bias}

Publication bias was assessed using Egger's test for small-study effects. There was no evidence of publication bias ( $p<0.0001)$. Begg's test also showed publication bias $(p=0.0001)$. In agreement with these findings, the funnel plot was asymmetric even after adjusting for potential publication bias by applying the trim-and-fill method (Figure 3).

\section{Sources of heterogeneity: Subgroup and regression analyses}

\section{Subgroup analysis}

Due to the marked heterogeneity observed, which can be ascribed to different estimate effect modifiers such as the diagnostic method employed in the individual studies, we performed subgroup analyses using these variables. Subgroup analysis found that the estimated DPN prevalence rates using screening questionnaires and clinical examination were $48 \%(95 \% \mathrm{Cl}[46 \%, 50 \%])$ and $40 \%(95 \% \mathrm{Cl}[38 \%, 42 \%])$, respectively, while the estimated prevalence using a nerve conduction study was $26 \%(95 \% \mathrm{Cl}[15 \%, 36 \%]$; Figure 4$)$. The $\mathrm{I}^{2}$ test revealed marked heterogeneity $\left(\mathrm{I}^{2}=98.2 \%\right.$ and $88.6 \%$, respectively, $\mathrm{p}<$ 0.001).

\section{Meta-regression analysis}

We further investigated the possible sources of between-study variation in our analysis by performing meta-regression analysis of sample size against publication year as variables of interest. The result of the meta-regression analysis showed that neither covariate was significantly associated with the presence of heterogeneity $(-0.0006,95 \% \mathrm{Cl}[-0.014,0.0129], \mathrm{p}=0.931$; Figure 5).

\section{Sensitivity analysis}

We carried out sensitivity analysis to evaluate the impact of each study on the pooled estimate of DPN prevalence. Using a random-effects model, our analysis showed that no single study influenced the overall prevalence of DPN (Figure 6).

\section{Discussion}

The current study found an overallprevalence of DPN in Saudi Arabia of 39\%. The estimated DPN prevalence in Saudi Arabia calculated in this analysis appears to be lower than reports from similar studies conducted in developing countries. ${ }^{15,44}$ Meta-analyses of observational studies in Iran and Africa reported estimated prevalence rates of $53 \%{ }^{44}$ and $46 \%,{ }^{15}$ respectively. In contrast, our result is higher than the prevalence findings in Oceania, the Americas, and Asia of $23.2 \%, 31.6 \%$, and $32.24 \%$, respectively. ${ }^{45}$ Similarly, the prevalence estimate obtained in the current study is higher than the global prevalence of DPN among people living with type $2 \mathrm{DM}$ of $35.78 \% .{ }^{45}$ This global variability in DPN prevalence has been ascribed to differences in regional characteristics and potential risk factors, including duration of DM, patient age, patient height, and glycemic control status. ${ }^{45}$

Although the pathomechanism of DPN remains largely unclear, it is increasingly recognized as involving a multitude of factors that include vascular occlusion of the vasa nervorum, deficiency of myoinositol with alteration of myelin synthesis, endothelial abnormality, hyperosmolarity with resultant nerve edema and disruption of the nerve architecture, dysfunction of sodium-potassium adenine triphosphatase, and the impacts of the accumulation of fructose and sorbitol. ${ }^{46}$ Peripheral nerve dysfunction in people with DPN is largely irreversible, which necessitates increased attention devoted to prevention through the identification of modifiable risk factors for DPN. ${ }^{47}$ To this end, previous studies have identified some common risk factors responsible for DPN in people living with DM, including duration of DM, patient age, gender, existence of microvascular complications, alcohol consumption, hypertension, obesity, cigarette smoking, physical inactivity, and glycated hemoglobin level. ${ }^{17,47,48}$ 
The prevalence of DPN reported by the studies included in the current meta-analysis varied widely, ranging from $20 \%{ }^{23}$ to $66.7 \% .{ }^{24}$ This discrepancy, which could be explained by heterogeneity in diagnostic method, was further explored by subgroup analysis based on the studies' method of case ascertainment, consisting of clinical examination (symptoms and signs), screening questionnaires, and electrodiagnostic testing. The primary screening questionnaires used in the studies included the Michigan Neuropathy Screening Instrument (MNSI), Neuropathy Symptom Score (NSS), and Neuropathy Disability Score (NDS). The sensitivity of MNSI (using a cut-off point of 2.0), NSS, and NDS are $65 \%, 82.05 \%$, and $92.3 \%$, respectively, and their specificities are $83 \%$, $66.67 \%$, and $47.62 \%$, respectively. ${ }^{45,49}$

The diagnostic methods employed differed among the studies due to differences in study aims. The prevalence of DPN based on the method of case ascertainment was highest (48\%) with screening questionnaires and lowest (26\%) with electrodiagnostic tests.

There is limited evidence indicating an ideal screening method for DPN. Nonetheless, there has been remarkable progress in the detection of DPN in people living with DM with particular reference to electrophysiological techniques and quantitative sensory tests. ${ }^{50}$

\section{Strengths and weaknesses of the study}

To the best of our knowledge, this meta-analysis is the first to quantitatively pool data from carefully selected studies to generate estimates of the magnitude of DPN in Saudi Arabia. The present meta-analysis was conducted based on PRISMA guidelines for meta-analyses of observational studies. We carried out a comprehensive search strategy to include studies from Saudi Arabia using stringent predetermined criteria, assessed the quality of the selected studies with a robust critical appraisal tool, employed multiple standardized methods to quantify publication bias in our study, and further explored the heterogeneity observed in the analysis using meta-regression and sensitivity analysis.

Despite the strengths of our study, this meta-analysis also has some limitations that warrant mentioning. First, only studies published in the English language were included in the analysis, introducing the potential to exclude relevant data published in other languages. Nevertheless, the official language of medical journals in Saudi Arabia is English; thus, the possibility of missing relevant non-English medical publications is low. Second, publication bias was found during our analysis. We made an effort to mitigate publication bias by attempting to retrieve related but unpublished work, and we statistically explored this by applying the trim-and-fill technique. It is worth noting that our results do not undervalue the fact that a robust, rigorous, well-designed, and well-conducted national epidemiological survey, performed concurrently across all regions of Saudi Arabia using a consistent methodological approach, would deliver a more reliable magnitude of DPN in Saudi Arabia. In the absence of such an effort, our findings provide robust estimates of the magnitude of DPN in Saudi Arabia and can guide the planning of prevention and treatment strategies for DPN in the kingdom. ${ }^{1,21,24}$

It is additionally important to note that the heterogeneity of clinical manifestations of DPN makes it difficult to identify patients at high risk for DPN. Therefore, early diagnosis is key to a better prognosis and prevention of diabetic foot ulcers, amputation, and DPN-related disability.

\section{Conclusion}

The present study found a prevalence of DPN in Saudi Arabia of 39\%, which is lower than average prevalence figures in developing countries but higher than average estimates from developed countries. The need for a sustained effort aimed at stemming the tide of DM in Saudi Arabia cannot be overemphasized.

\section{Declarations}

Ethics approval and consent to participate : NA

Consent for publication: NA

Competing interests: None

Funding: This research was funded by the Ministry of Education, Saudi Arabia through the Deputyship for Research and Innovation (Project number:UB-511442).

Authors' contributions: Conceptions and designs: OLF, MA. Literature search, article selection: OLF, BA, AMJ, MA. Analysis: OLF and MAJ. Manuscript drafting: All authors. Manuscript Revision: All authors. Approval of the final version of the manuscript: All authors.

Acknowledgements: None

Availability of Data and Materials: All data generated or analyzed during this study are included in this published article.

\section{References}

1. Liu X, Xu Y, An M, Zeng Q. The risk factors for diabetic peripheral neuropathy: A meta-analysis. PLOS ONE. 2019;14:e0212574.

2. Tesfaye S, Boulton AJM, Dyck PJ, Freeman R, Horowitz M, Kempler P, et al. Diabetic neuropathies: update on definitions, diagnostic criteria, estimation of severity, and treatments. Diabetes Care. 2010;33:2285-93.

Page 5/10 
3. Argoff CE, Cole BE, Fishbain DA, Irving GA. Diabetic peripheral neuropathic pain: clinical and quality-of-life issues. Mayo Clin Proc. 2006;81:S3-11.

4. Iqbal Z, Azmi S, Yadav R, Ferdousi M, Kumar M, Cuthbertson DJ, et al. Diabetic Peripheral Neuropathy: Epidemiology, Diagnosis, and Pharmacotherapy. Clin Ther. 2018;40:828-49.

5. Shiferaw WS, Akalu TY, Work Y, Aynalem YA. Prevalence of diabetic peripheral neuropathy in Africa: a systematic review and meta-analysis. BMC Endocr Disord. 2020;20:49.

6. Statistical Yearbook - Statistical Yearbook [Internet]. [cited 2021 Jan 13]. Available from:

https://www.moh.gov.sa/en/Ministry/Statistics/book/Pages/default.aspx

7. Owolabi LF, Adamu B, Imam Al, Owolabi SD, Alhaji ID, Al-Ghamdi MA, et al. Systematic review and meta-analysis estimating the prevalence, burden, and trend of diabetes mellitus in Saudi Arabia. J Diabetes Endocr Pract. 2020;3:1.

8. Halawa MR, Karawagh A, Zeidan A, Mahmoud A-E-DH, Sakr M, Hegazy A. Prevalence of painful diabetic peripheral neuropathy among patients suffering from diabetes mellitus in Saudi Arabia. Curr Med Res Opin. 2010;26:337-43.

9. Genuth S, Eastman R, Kahn R, Klein R, Lachin J, Lebovitz H, et al. Implications of the United kingdom prospective diabetes study. Diabetes Care. 2003;26 Suppl 1:S28-32.

10. Gordois A, Scuffham P, Shearer A, Oglesby A, Tobian JA. The health care costs of diabetic peripheral neuropathy in the US. Diabetes Care. 2003;26:1790-5.

11. Barbosa AP, Medina JL, Ramos EP, Barros HP. Prevalence and risk factors of clinical diabetic polyneuropathy in a Portuguese primary health care population. Diabetes Metab. 2001;27:496-502.

12. Naeem Z. Burden of Diabetes Mellitus in Saudi Arabia. Int J Health Sci. 2015;9:5-6.

13. Amani Y. Prevalence and associated risk factors of diabetic peripheral neuropathy among diabetic patients in National Center of Diabetes in Yemen [Internet]. undefined. 2014 [cited 2021 Mar 2]. Available from: /paper/Prevalence-and-associated-risk-factors-of-diabetic-

Amani/dea2c465179888e54c4f406c1ebc395a5d6509aa

14. Katulanda P, Ranasinghe P, Jayawardena R, Constantine GR, Sheriff MHR, Matthews DR. The prevalence, patterns and predictors of diabetic peripheral neuropathy in a developing country. Diabetol Metab Syndr. 2012;4:21.

15. Shiferaw WS, Akalu TY, Work Y, Aynalem YA. Prevalence of diabetic peripheral neuropathy in Africa: a systematic review and meta-analysis. BMC Endocr Disord. 2020;20:49.

16. Khawaja N, Abu-Shennar J, Saleh M, Dahbour SS, Khader YS, Ajlouni KM. The prevalence and risk factors of peripheral neuropathy among patients with type 2 diabetes mellitus; the case of Jordan. Diabetol Metab Syndr. 2018;10:8.

17. Bansal D, Gudala K, Muthyala H, Esam HP, Nayakallu R, Bhansali A. Prevalence and risk factors of development of peripheral diabetic neuropathy in type 2 diabetes mellitus in a tertiary care setting. J Diabetes Investig. 2014;5:714-21.

18. Lu B, Hu J, Wen J, Zhang Z, Zhou L, Li Y, et al. Determination of peripheral neuropathy prevalence and associated factors in Chinese subjects with diabetes and pre-diabetes - ShangHai Diabetic neuRopathy Epidemiology and Molecular Genetics Study (SH-DREAMS). PloS One. 2013;8:e61053.

19. Bouhassira D, Letanoux M, Hartemann A. Chronic pain with neuropathic characteristics in diabetic patients: a French cross-sectional study. PloS One. 2013;8:e74195.

20. Van Acker K, Bouhassira D, De Bacquer D, Weiss S, Matthys K, Raemen H, et al. Prevalence and impact on quality of life of peripheral neuropathy with or without neuropathic pain in type 1 and type 2 diabetic patients attending hospital outpatients clinics. Diabetes Metab. 2009;35:206-13.

21. Dyck PJ, Kratz KM, Karnes JL, Litchy WJ, Klein R, Pach JM, et al. The prevalence by staged severity of various types of diabetic neuropathy, retinopathy, and nephropathy in a population-based cohort: the Rochester Diabetic Neuropathy Study. Neurology. 1993;43:817-24.

22. Garoushi. Point prevalence of painful diabetic neuropathy in the Middle East and North Africa region: A systematic review with meta-analysis [Internet]. [cited 2021 Jan 18]. Available from: https://www.ljmsonline.com/article.asp?issn=2588-

9044;year=2018; volume=2;issue=3;spage=85; ;page=94; aulast=Garoushi

23. Kasim K, Nozha OA. PREVALENCE AND RISK FACTORS OF PERIPHERAL NEUROPATHY IN DIABETIC PATIENTS ATTENDING PRINCE ABDUL AZIZ BIN MAJED DIABETES CENTRE IN MADINAH, SAUDI ARABIA. J Dis Glob Health. 2015;16-22.

24. Algeffari MA. Painful Diabetic Peripheral Neuropathy among Saudi Diabetic Patients is Common but Under-recognized: Multicenter Cross-sectional study at primary health care setting. J Fam Community Med. 2018;25:43-7. 
25. Stroup DF, Berlin JA, Morton SC, Olkin I, Williamson GD, Rennie D, et al. Meta-analysis of observational studies in epidemiology: a proposal for reporting. Meta-analysis Of Observational Studies in Epidemiology (MOOSE) group. JAMA. 2000;283:2008-12.

26. Moher D, Liberati A, Tetzlaff J, Altman DG, PRISMA Group. Preferred reporting items for systematic reviews and meta-analyses: the PRISMA statement. Ann Intern Med. 2009;151:264-9, W64.

27. DerSimonian R, Laird N. Meta-analysis in clinical trials. Control Clin Trials. 1986;7:177-88.

28. Egger M, Smith GD, Schneider M, Minder C. Bias in meta-analysis detected by a simple, graphical test. BMJ. 1997;315:629-34.

29. Begg CB, Mazumdar M. Operating characteristics of a rank correlation test for publication bias. Biometrics. 1994;50:1088-101.

30. Higgins JPT, Thompson SG, Deeks JJ, Altman DG. Measuring inconsistency in meta-analyses. BMJ. 2003;327:557-60.

31. Nielsen JV. Peripheral neuropathy, hypertension, foot ulcers and amputations among Saudi Arabian patients with type 2 diabetes. Diabetes Res Clin Pract. 1998;41:63-9.

32. Akbar DH, Mira SA, Zawawi TH, Malibary HM. Subclinical diabetic neuropathy: a common complication in Saudi diabetics. Saudi Med J. 2000;21:4337.

33. Ahmed AA, Algamdi SA, Algurashi A, Alzhrani AM, Khalid KA. Risk factors for diabetic foot ulceration among patients attending primary health care services « Journal of Diabetic Foot Complications [Internet]. [cited 2021 Mar 3]. Available from: https://jdfc.org/spotlight/risk-factors-for-diabetic-footulceration-among-patients-attending-primary-health-care-services/

34. Wang DD, Bakhotmah BA, Hu FB, Alzahrani HA. Prevalence and Correlates of Diabetic Peripheral Neuropathy in a Saudi Arabic Population: A CrossSectional Study. PLoS ONE [Internet]. 2014 [cited 2021 Mar 3];9. Available from: https://www.ncbi.nlm.nih.gov/pmc/articles/PMC4153691/

35. Kasim K, Al Nozha O. Prevalence and risk factors of peripheral neuropathy in diabetic patients attending prince Abdul Aziz bin Majed Diabetes Centre in Madinah, Saudi Arabia. J Dis Glob Health. 2015;2:1-7.

36. Sheshah E, Algreeshah F, Al-Madani K, Al-Qaisi D, Madanat A. Diabetic peripheral neuropathy and sudomotor dysfunction in saudi patients with newly diagnosed type 2 diabetes mellitus. J Diabetes Metab Disord Control [Internet]. 2017 [cited 2021 Mar 3];Volume 4. Available from:

https://medcraveonline.com/JDMDC/JDMDC-04-00108.pdf

37. Aljehani MM, Mohamed AM, Ali AH, Alhaeti HR, Alribh FM, Alharbi F, et al. Prevalence of Diabetic Complications in Relation to Risk Factors amongPatients with Type 2 Diabetes at University Hospital in Riyadh, Saudi Arabia [Internet]. undefined. 2019 [cited 2021 Mar 3]. Available from: /paper/Prevalence-of-Diabetic-Complications-in-Relation-to-Aljehani-Mohamed/e070cda015d9299ea1a2a840c03420b20f862fd5

38. Sendi RA, Mahrus AM, Saeed RM, Mohammed MA, Al-Dubai SAR. Diabetic peripheral neuropathy among Saudi diabetic patients: A multicenter crosssectional study at primary health care setting. J Fam Med Prim Care. 2020;9:197-201.

39. Almohaysen AAALMAKKARHAAMAFAAHAAGM. Prevalence and risk factors of diabetic neuropathy in Qassim, Saudi Arabia. Majmaah J Health Sci. 2020;8:23-31.

40. Mojaddidi M, Moutasem A, Al Nozha MO, Elbab MF. Early Diagnosis of Diabetic Neuropathy in Almadinah Almunawwarah. J Taibah Univ Med Sci [Internet]. [cited 2021 Mar 3]; Available from:

https://www.academia.edu/33614015/Early_Diagnosis_of_Diabetic_Neuropathy_in_Almadinah_Almunawwarah

41. Aleidan FA, Ahmad BA, Alotaibi FA, Aleesa DH, Alhefdhi NA, Badri M, et al. Prevalence and Risk Factors for Diabetic Peripheral Neuropathy Among Saudi Hospitalized Diabetic Patients: A Nested Case-Control Study</p> [Internet]. Vol. 13, International Journal of General Medicine. Dove Press; 2020 [cited 2021 Mar 3]. p. 881-9. Available from: https://www.dovepress.com/prevalence-and-risk-factors-for-diabetic-peripheral-neuropathy-among-s-peerreviewed-article-IJGM

42. Khan AR, Al Abdul Lateef ZN, Fatima S, Al Yousuf SAA, Khan Afghan SZ, Al Marghani S. Prevalence of chronic complication among type 2 diabetics attending primary health care centers of Al Ahsa district of Saudi Arabia: a cross sectional survey. Glob J Health Sci. 2014;6:245-53.

43. Al-Tahan A. The pattern of peripheral neuropathy in Saudi Arabia: the experience at King Khalid University Hospital 1983-1990 | Virtual Health Sciences Library [Internet]. 2019 [cited 2021 Mar 3]. Available from: https://vlibrary.emro.who.int/imemr/the-pattern-of-peripheral-neuropathy-in-saudi-arabia-theexperience-at-king-khalid-university-hospital-1983-1990/

44. Sobhani S, Asayesh H, Sharifi F, Djalalinia S, Baradaran HR, Arzaghi SM, et al. Prevalence of diabetic peripheral neuropathy in Iran: a systematic review and meta-analysis. J Diabetes Metab Disord. 2014;13:97.

45. Souza LR de, Debiasi D, Ceretta LB, Simões PW, Tuon L. Meta-Analysis And Meta-Regression Of The Prevalence Of Diabetic Peripheral Neuropathy Among Patients With Type 2 Diabetes Mellitus. Int Arch Med [Internet]. 2016 [cited 2021 Feb 13];9. Available from:

Page $7 / 10$ 
http://imed.pub/ojs/index.php/iam/article/view/1526

46. Tomic-Canic M, Brem H. Gene array technology and pathogenesis of chronic wounds. Am J Surg. 2004;188:67-72.

47. Won JC, Park TS. Recent Advances in Diagnostic Strategies for Diabetic Peripheral Neuropathy. Endocrinol Metab Seoul Korea. 2016;31:230-8.

48. Liu X, Xu Y, An M, Zeng Q. The risk factors for diabetic peripheral neuropathy: A meta-analysis. PloS One. 2019;14:e0212574.

49. Moghtaderi A, Bakhshipour A, Rashidi H. Validation of Michigan neuropathy screening instrument for diabetic peripheral neuropathy. Clin Neurol Neurosurg. 2006;108:477-81.

50. Mythili A, Kumar KD, Subrahmanyam K a. V, Venkateswarlu K, Butchi RG. A Comparative study of examination scores and quantitative sensory testing in diagnosis of diabetic polyneuropathy. Int J Diabetes Dev Ctries. 2010;30:43-8.

\section{Tables}

Table 1: Showed the results of quality assessment based on AHRQ quality standards

\begin{tabular}{|c|c|c|c|c|c|c|c|c|c|c|c|c|}
\hline Study ID & $\begin{array}{l}\text { Define } \\
\text { the } \\
\text { source }\end{array}$ & $\begin{array}{l}\text { List } \\
\text { criteria }\end{array}$ & $\begin{array}{l}\text { Indicate } \\
\text { time }\end{array}$ & $\begin{array}{l}\text { Indicate } \\
\text { subjects }\end{array}$ & $\begin{array}{l}\text { Indicate } \\
\text { mask }\end{array}$ & $\begin{array}{l}\text { Describe } \\
\text { assessment }\end{array}$ & $\begin{array}{l}\text { Explain } \\
\text { exclusion }\end{array}$ & $\begin{array}{l}\text { Describe } \\
\text { confounding }\end{array}$ & $\begin{array}{l}\text { Hand } \\
\text { missing }\end{array}$ & Summarize & $\begin{array}{l}\text { Follow- } \\
\text { up }\end{array}$ & Total \\
\hline $\begin{array}{l}\text { Nielson et } \\
\text { al }\end{array}$ & 1 & 1 & 1 & 1 & 1 & 1 & 1 & 1 & 0 & 0 & 0 & 8 \\
\hline $\begin{array}{l}\text { Akbar et } \\
\text { al }\end{array}$ & 1 & 1 & 1 & 1 & 1 & 1 & 1 & 0 & 0 & 0 & 0 & 7 \\
\hline $\begin{array}{l}\text { Mojaddidi } \\
\text { et al }\end{array}$ & 1 & 1 & 1 & 1 & 1 & 1 & 1 & 0 & 0 & 0 & 0 & 7 \\
\hline $\begin{array}{l}\text { Halawa et } \\
\text { al }\end{array}$ & 1 & 1 & 1 & 1 & 1 & 1 & 1 & 1 & 0 & 0 & 0 & 8 \\
\hline $\begin{array}{l}\text { Ahmed et } \\
\text { al }\end{array}$ & 1 & 1 & 1 & 1 & 1 & 1 & 0 & 0 & 0 & 0 & 0 & 6 \\
\hline $\begin{array}{l}\text { Wang et } \\
\text { al }\end{array}$ & 1 & 1 & 1 & 1 & 1 & 1 & 1 & 1 & 1 & 0 & 0 & 9 \\
\hline $\begin{array}{l}\text { Kasim et } \\
\text { al }\end{array}$ & 1 & 1 & 1 & 1 & 1 & 1 & 1 & 1 & 0 & 0 & 0 & 8 \\
\hline $\begin{array}{l}\text { Shesha et } \\
\text { al }\end{array}$ & 1 & 1 & 1 & 1 & 1 & 1 & 1 & 0 & 0 & 0 & 0 & 7 \\
\hline $\begin{array}{l}\text { Shesha et } \\
\text { al }\end{array}$ & 1 & 1 & 1 & 1 & 1 & 1 & 0 & 1 & 0 & 0 & 0 & 7 \\
\hline $\begin{array}{l}\text { Algeffari } \\
\text { et al }\end{array}$ & 1 & 1 & 1 & 1 & 1 & 1 & 0 & 0 & 0 & 0 & 0 & 6 \\
\hline Aljehani & 1 & 1 & 1 & 1 & 1 & 1 & 1 & 0 & 0 & 0 & 0 & 7 \\
\hline $\begin{array}{l}\text { Sendi at } \\
\text { al }\end{array}$ & 1 & 1 & 1 & 1 & 1 & 1 & 1 & 1 & 0 & 0 & 0 & 8 \\
\hline $\begin{array}{l}\text { Almohisen } \\
\text { et al }\end{array}$ & 1 & 1 & 0 & 1 & 1 & 1 & 1 & 1 & 0 & 0 & 0 & 7 \\
\hline
\end{tabular}

Table 2: Showed the characteristics of the included studies 


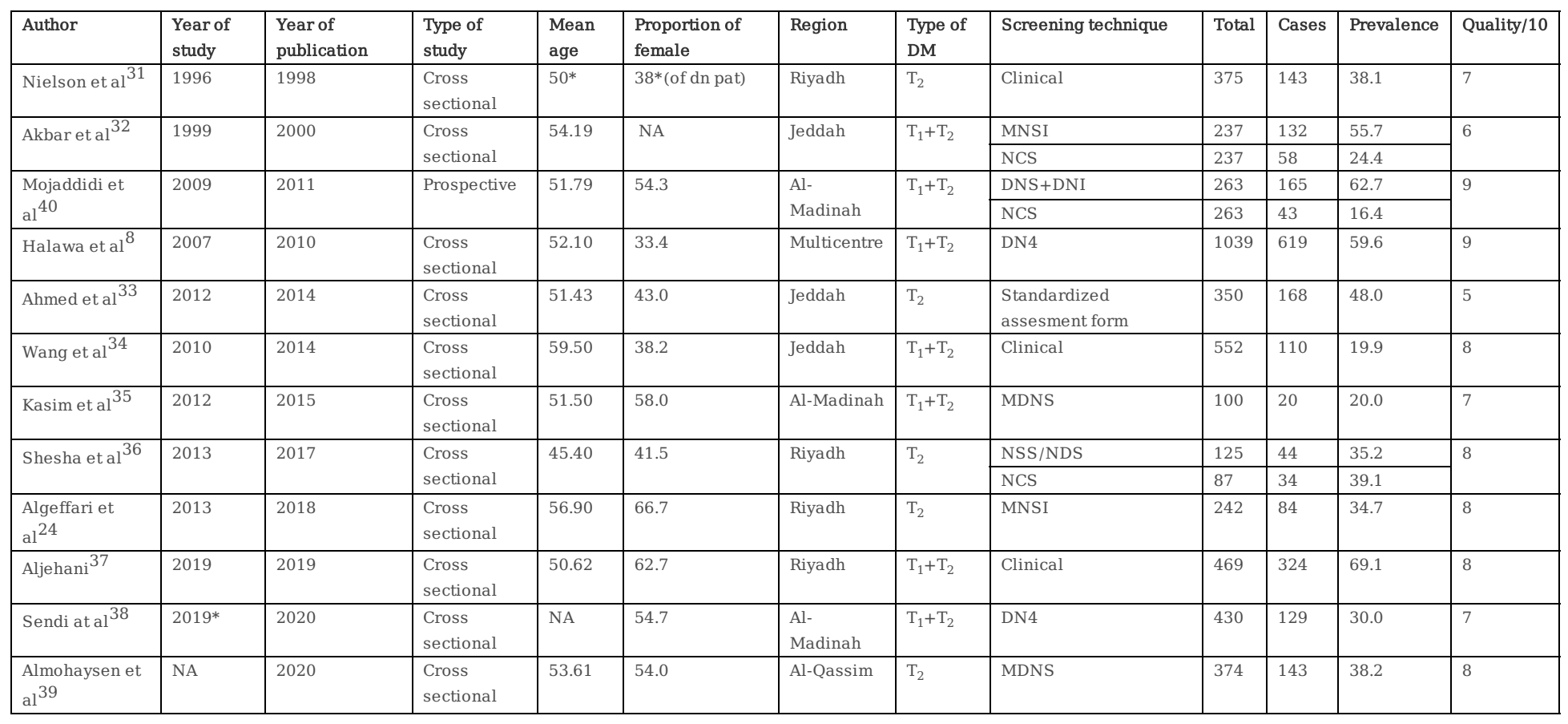

*T $\mathrm{T}_{1}$ :Type-1DM, $\mathrm{T}_{2}:$ Type-2DM,NCS: Nerve conduction study, MNSI: Michigan Neuropathy Screening Instrument, MDNS: Michigan Diabetic Neuropathy Score, DN4: DN4 assessment tool, NSS: Neurological symptom score, NDS: Neuropathy Disability Score

\section{Figures}
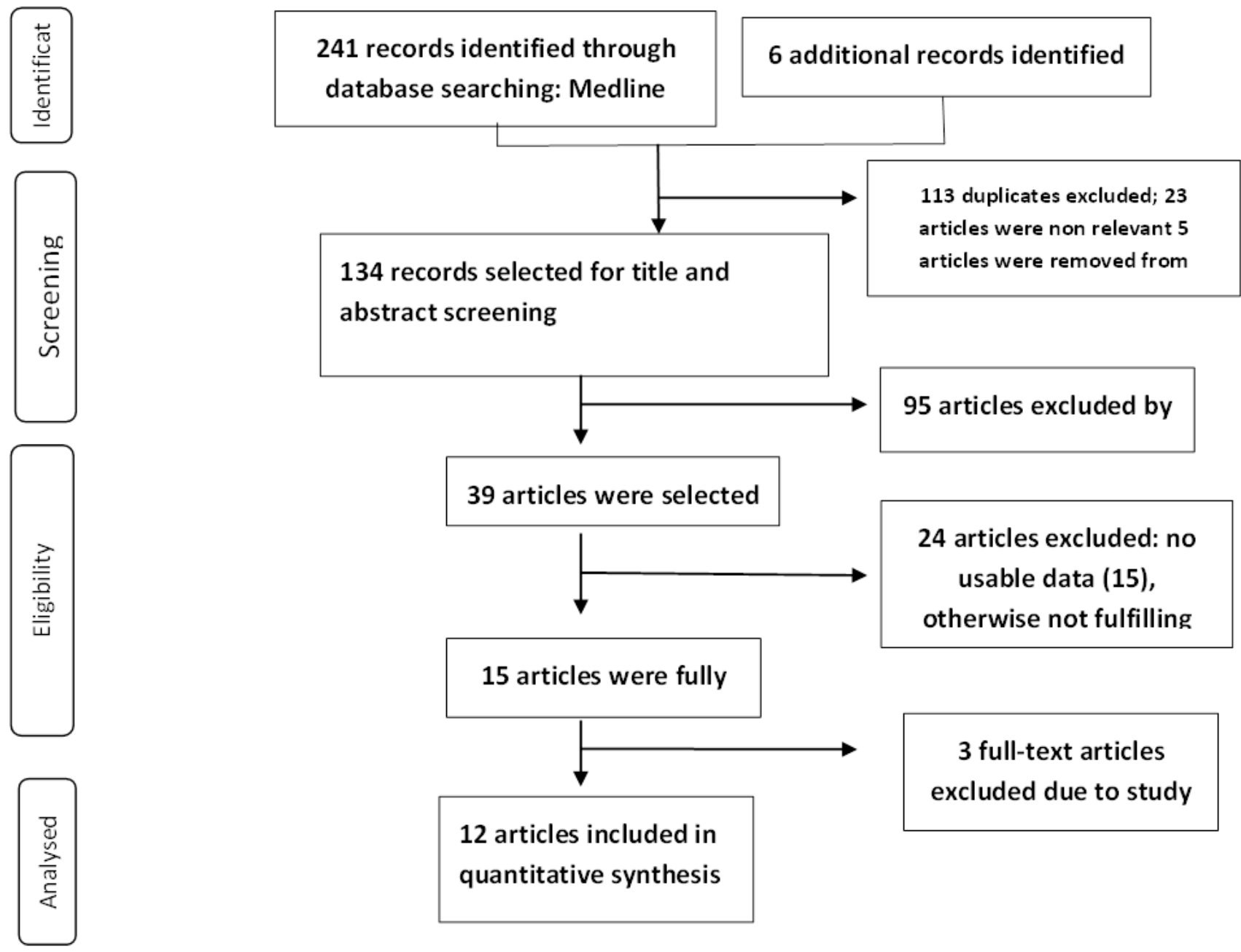

\section{5 articles excluded by}

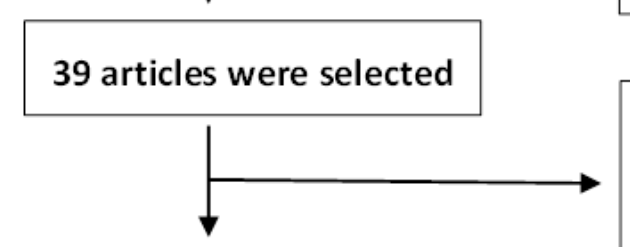

24 articles excluded: no usable data (15), otherwise not fulfilling

\section{5 articles were fully}

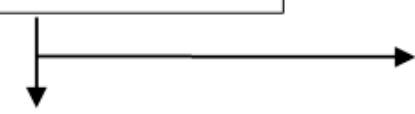

3 full-text articles excluded due to study

12 articles included in quantitative synthesis 
Figure 1

PRISMA Flow diagram showing the process of selection of articles for the meta-analysis

\section{Figure 2}

Forest plot of studies included in meta-analysis with pooled prevalence of DPN (39\%) in Saudi Arabia

\section{Figure 3}

Funnel plots showing graphic representation of Publication bias with Funnel plot of the included studies (A) and using Trim and Fill method (B)

\section{Figure 4}

Forest plot showing subgroup prevalence estimates on method of diagnosis

\section{Figure 5}

Meta-regression plot showing the trend in DPN prevalence over the years

\section{Figure 6}

Sensitivity analysis showing no significant influence of any of the included studies on the others 